considering, on which further investigation will throw more light, and will bring into more harmony as that light is imparted. In physics, the universality of wave-motion, as the connecting link between mind and matter, recommends itself by its comprehensive grandeur : and the prin. ciple involved in the correlation or conservation of physical forces-that force or energy, like matter, may be transferred or converted but not annihilated-has opened a wide field for 'investigation in its relation to physiology. All seems to point in one direction-to the inclusiveness of the laws and the simplicity of the instruments by which such varied, such complex results are obtained; and in this contemplation the mind is elevated by the conviction which is forced upon it, that the relative quality of magnitude is, like time, simply an accommodation to our firite intelligence: the myriads of worlds on which we gaze in the infinity of space, individually of bulk too vast to be encircled by the earth's orbit around the sun, and the microcosm of our own bodies, yea, even the animalctle which is invisible to our unaided sense, are framed by the same Omripotence, and governed by the same Omniscience;-and that each is perfect in its own degree, and equally cared for, in the adaptation of the laws which determine its existence, and secure the fulfilment of is destiny.

\section{NOTES ON THE TREATMENT OF CHOLERA.}

\section{By T. M. LOWNDS, M.D., Bombay Army.}

IT is with some diffidence that I submit the following remarks on the treatment of cholera, as the plan which I havc for some years pursued is so different from that so ably advocated by Dr. George Johnson, and endorsed by so high an authority as Sir Thomas Watson; but I saw such immediate relief follow the administration of nutriment, of a kind to be described presently, in collapse, and in a very large proportion of cases the disease ran a course so different from what I had seen previously, and went on to curc, that I am disposed to submit an abstract for the consideration of those of my professional brethren in England, who, unfortunately, have now comparatively so many opportunities of treating this intractable destroyer.

In 1860, I published some remarks in the Transactions of the Bombay Medical and Physical Society on what I considered should be the rational treatment of cholera; and in these remarks I divided cholera into four stages : 1, preliminary diarrhœe ; 2, true cholera with vomiting and purging of the characteristic rice-water evacuations; 3 , collapse ; and 4 reaction. I may briefly state that I considered the disease to consist, pathologically, in a blood-poison, devitalising the blood to such an extent in fatal cases, as to cause death at the lungs from the inability of the blood-corpuscles to assimilate oxygen.

For the treatment of the first stagc, I then used astringents, with one or two full doses of opium, with which stimulants, of either the alcoholic or the ammoniacal class, might be advantageously combined. I considered that both opium and alcohol should be used with caution, because the disease might run on to the second stage, and we might be embarrassed by having carbonised the blood or locked up the secretions to too great an extent. Calomel I sometimes gave in this stage. In the second stage, the caution with regard to opium must be increased. Calomel should be given freely, sinapisms applied, and thirst allayed with some fluid capable of yielding oxygen to the blood; dry heat should be applied to the body and limbs. In the third stage, oxygenated drinks and light nourishment, such as Liebig's cold soup, must be given. The fourth stage is to be treated on general principles.

With respect to the treatment of the first stage, I have, since the time when my remarks were written, omitted entirely the use of astringents, finding that a draught containing fifteen or twenty minims of chloroform, with ten or fifteen minims of tincture of opium, with a drachm of spirit to render the chloroform miscible with water, was exceedingly efficacious. During several years, when cholera was more or less prevalent, I have treated a large number of patients by this method, and can only call to mind one case where the disease progressed to collapse, and two cases where diarrhœea went on to rice-water purging and vomiting.* It may be objected to this, that these cases were not choleraic purging ; but the vast majority of them occurred during the time when cholera was present, and the symptoms supervened between midnight and five in the morning, with crampy pains in the stomach and bowels. These cases in India are specially suspicious, the patient going to bed quite well, and being awakened at the time named. During the prevalence of severe cholera, the same result was observed. The orders issued were, that every person suffering from diarrhœa was at once to come to hospital

\footnotetext{
- All did well.
}

for treatment; and this medicine was administered, with the general re. sult that but few required a second dose.

The following are the notes of two cases of cholera, treated as I have stated.

CASE 1. -Kublee, sepoy, aged about 25, was admitted May 22nd, 1866, at 10 A.M., complaining that he had much pain in the stomach, and saying that he had been purged three or four times during the previous evening, and that vomiting of white fluid had come; on in the night. Pulse small and quick; anxious expression of face. He was ordered to have immediately fifteen minims of chloroform, ten minims of tincture of opium, and a drachm of spirit, in an ounce of water; and to have a mustard-poultice applicd. I was then called by the native doctor, and found that for the time the vomiting had abated ; the pulse was very small and quick. He was ordered to have five grains of calomel im. mediately; and the following drink every hour, or more frequently, in ounce doses.

Bo Potass.chlorat. $\mathrm{jj}$; acidi hydrochlorici fort. m $\mathrm{R}$ viij ; acidi nitrici dilut. ziss; aquæ ३̧xxiv. $M$.

During the next four or five hours, he was purged two or three times, and vomited many times, all rice-water evacuations. I saw him again at 3.30 P.M. He was collapsed; the eyes were sunken; the skin cold, but no sweating; the pulse barely perceptible, and that only at intervals. The poice was choleraic. He was ordered to repeat the calomel and chloroform, without the tincture of opium. At 4 P.M., I gave half an ounce of arrack in water, which was immediately vomited. He was ordered to have an ounce of Liebig's cold soup every half hour; and to continue the chlorate of potass drink. No raw meat could be procured, but a quantity of the soup was made from a freshly killed fowl, and he had the first dose about 5 P.M. At 7 , I saw him again. No vomiting nor purging; pulse markedly improved; skin warmer.

May $23 \mathrm{rd}, 8$ A.M. He had vomited twice in the night, and once had been purged, both rice-water evacuations. Pulse better; skin warmer. He had passed a little urine. The soup and chlorate of potass drink were continued. In the evening, he had romited only once; the pulse was improving. The treatment was continued.

May 24th. He was much the same. The inedicines were continued. In the evening, there was reaction with a full pulse; the skin was hotter than natural. Sago and light food were allowed; and he was ordered to continue the chlorate of potass drink.

Occasional vomiting supervened up to the 27 th, when he appeared much better. The secretions had gradually returned.

May 28th. He wished to be discharged; and on the 29th was discharged, well and strong.

CASE II.-Rajica, Bheel sepoy, was admitted on May 22nd, at 8 P.M., from the same guard as the previous patient, and with the same symptoms. Chloroform mixture and calomel were given, and a mustard-poultice applied. Liebig's soup was'ordered to be given frequently.

May 23rd. The pulse was just perceptible. There was no sweating. The cholera appearance was fully developed. The urine was quite suppressed. He vomited still, and had been purged twice, with rice-water evacuation. He was ordered to continue the soup and the chlorate of potass drink.

May 24th. The pulse was decidedly improved. The skin was naturally warm. He still vomited three or four times in twelve hours. No urine was passed. The treatment was continued. In the evening, hiccough had commenced, and was urgent. Pulse good. No urine.

May 25th. There was still much hiccough. He had passed no urine; and was still purged, but not much.

May 26th. He was still slightly purged. He was ordered to continue the soup and the chlorate of potass drink; and to have five grains of calomel, and a sinapism applied. He passed urine at 12 to-day for the first time. In the evening, the pulse was good; the skin natural. He had hiccough

May 27th. He slept well; had been purged thrice in the night. The first was a natural bilious stool; the second and third were rice-water. He was ordered to continue the chlorate of potass drink; and to have sago-diet, etc.

May 28th. He had still hiccough ; but seemed well otherwise.

May 29th. The hiccough stopped to.day.

June 2nd. He was discharged well.

A woman, the wife of one of the sepoys of the same guard, was ad. mitted on May 23 rd. She died two and a half hours afterwards, having been treated in the same way.

Another case was admitted on May 24th, and followed the same course as the first two detailed. The man was from 35 to 40 years of age, and much weaker. Yet the course was precisely that of the first two cases detailed, except that urine was not passed for three and a half days, and there was no hiccough.

At the same time, I treated a considerable number of cases of chole- 
raic diarrhoen, and two or three cases where the disease had advanced so mweh as to be fairly designated cholera, as rice-water purging and vo. miting were present-all did well.

This (1866) was the third year in which I had thus, or nearly thus, treated cholera, and in each year the same results were observed; viz., I, the heat returned to the body gradually; 2 , the pulse improved very gradually; 3 , the sunken features regained their fulness long before reaction (i.e., a return of natural secretion and excretion) fairly ensued; 4 cramps, when present, speedily diminished. In November 1866, when the camp to which I was attached was at Agra, cholera broke out, and the first six cases were almost immediately fatal. The first two cases were collapsed almost hopelessly when first seen, and four others broke out very speedily among different parts of the establishment. An immediate move to an open plain, five miles distant, was requisite, and consequent on this no soup was administered until late next day. One other case died, and his sickness was not made known until he was pulselessly collapsed, having been ill more than twenty-four hours. In this short outbreak, fifty per cent. of the cases of cholera died; but treatment, in six out of fourteen, was much interfered with owing to the necessity for moving; and, as I said, the soup could not be made until next day. The seventh fatal case did not come under treatment until upwards of twenty-four hours after seizure.

Two of the cases were exceedingly severe, and pulled through after three and three and $a$ half days suppression of urine. In one of these cases, the red cold soup of Liebig passed through the intestine unchanged. When this was mentioned to me, I found, on inquiring, that the quantities of soup given to this patient, whose age was 12, were the same as to an adult. I reduced the quantity, and the redness at once ceased. I attributed this redness to the amount of soup being too lange to be absorbed. The second severe case suffered from sponginess of the gums, and frothy discharge of blood from the larynx, for many days after all symptoms of cholera had vanished.

I regret that I have not the data for showing, in a tabular form, the results by this method of treatment; but, out of twenty-five cases of cholera, sixteen recoveries took place. This includes.every case admitted, and the seven cases referred to at Agra, when circumstances prevented anything like a fair trial of the remedy.

Statistics I cannot rely on for showing the benefit of the treatment; for these are not at hand, and cholera has been, happily, but an infrequent visitor at Mount Aboo, where I was stationed for ten years. But the course of the disease in the two cases that $I$ have narrated, and which was precisely similar in the remainder, proved to me that, in those cases, Liebig's cold soup (vide Ranking's Abstract, vol. xxi, page 357) had very marked power in keeping up a feeble circulation and strengthening the system, so as to enable it to throw off the poison by the natural channels, and thus carry the patient through the disease.

The earliest signs of improvement, in my experience, have been increased heat of skin and an improvement in the pulse; no sweating took place in any case, This marked amelioration in the condition of patients preceded any return of secretion by as much as three days or three days and a half. In one case, a bilious stool on the fifth night of the disease wras followed by two others of rice-water.

I am sure that the soup was absorbed, as only in one case have I seen, in the matter ejected by stool, any resemblance to it; and it has not been returned unchanged by vomiting to my knowledge. I have never known it cause vomiting. In one case, when considerably improved, the patient said he disliked the soup, and craved for arrowroot. It was given, but immediately produced vomiting. He then took the soup without any difficulty.

Sometimes the state of complete reaction comes on almost insensibly; the return of the urine coinciding with bilious secretion, without any febrile disturbance. In the few cases (twenty-five) I have treated on this plan, I have not had any sequela to call for anxiety or notice.

The soup was first given in 1860, in consultation with Dr. Ogilvy, then of Her Majesty's 33rd Regiment, whose remark as to its probable action was to the effect it seemed to supply to the blood what was removed by the purging. This, after careful consideration, I still think is the correct explanation. I would not wish to enter into any discussion in these short notes as to the pathology of collapse; but it will be seen I cannot altogether agree with Dr. G. Johnson's argument, able though it be. I think that the cases of sudden collapse, with little vomiting and little or no purging, admit of a different interpretation to what he has assigned.

The soup was made by placing eight or ten ounces of finely minced raw meat in one pint of cold water, to which eight drops of strong muriatic acid had been added, stirring with a bit of stick occasionally for ten minutes, and then straining. The soup will only keep good a few hours; but if a supply of lean meat be kept ready minced, it can be made almost as wanted. Salt should always be added.
Hitherto, I have only given the soup when collapse was established; now I should be inclined to give it in any case where diarrhcea is ac. companied with a failing pulse, and most assuredly when the characteristic discharges of cholera have come on. In cholera infantum, or urgent diarhoea, I have not had much experience; but the soup apparently saved the life of a child of my own in the first named disease. The child was a year old, very robust and strong; and, in twenty hours after the first attack, the eyes were sunken. For three weeks, while it lasted, the soup was the on'y thing that could be retained, though nourishment of every available kind was tried, yet each seemed to cause vomiting. At the end of three weeks, the child was emaciated to a degree, had bed-sores, and much irritation about the anus; yet, under change of air, he was gradually able to take other nourishment; for, one day, he took raw meat minced, and tlen turned from that and the sonp with loathing. But, with pepsine, ke gradually digested other food, and did well. During all the time, there were no rice-water evacuations.

I believe that at first, especially in collapse, the soup should be adninistered in small, but frequently repeated, doses. I generally give in ounce or two every hour, or sometimes every half hour, alternating it vith the chlorate of potass drink. Water, cold or iced, in small quantities. I publish these notes at this time, as diarrhoea is now so prevalent in many large towns, and some may perhaps deem Liebig's soup worthy of a trial. I have given it to children three months old, generally omitfing the muriatic acid. Has Dr. Richardson's solution of the peroxide of bydrogen been tried as a drink in cholera?

\section{OBSTETRIC MEMORANDA.}

[UNDER this head, we shall, from time to time, as materials come to hand from correspondents, publish records of cases remarkable in themselves, or illustrating points of interest in obstetric practice, therapeutic or manipulative. We shall probably in this way preserve from oblivion the notes of very many useful and instructive occurrences in private practice; for the great obstetric experience is that-for the most part hitherto unwritten - of the great body of general practitioners throughout Great Britain. We will only ask those who may forward cases for record, to relate them with the utmost brevity, and equally to condense any appended remarks.]

\section{HEAD-AND-HAND PRESENTATION.}

By W. Ellis Clendinnen, Esq., Cheswardine.

MrS. M. was in labour with her sixth child on April 27th, 1868 . On my arrival, I found the head presenting; the pains regular; the os partially dilated. On examination one hour subsequently, I discovered that the fingers of the right hand had come down with the head. I immediately sent for my friend Mr. Morris, who had attended this patient in her last labour, which was a similar case, fifteen months previously. We delivered by turning. The child is alive and thriving at this date. The mother made a rapid recovery.

This was the second case of head-and-hand presentation within our own knowledge; and we have good grounds for supposing it to be the fourth. The patient informed us that the two previous children had been turned; whether they were hand presentations, or hand and head, she was, of course, unable to say. There are three children now living. The first two labours were natural. The eldest child, a girl, is idiotic, which the mother attributes to a fright she received during pregnancy. The second, also a girl, is paraplegic. It is remarkable, as Dr. Masters says, that two such cases should occur in a short space of time to one practitioner; but it is more remarkable, that four cases of head-andhand presentation, or at least two cases of head-and-hand, and two of hand presentation, should occur in the same woman, following two cases of natural labour.

\section{EXTRAUTERINE PREGNANCY.}

\section{By HENRY Ewen, Esq., Long Sutton.}

The following is the sequel of the case of extrauterine pregnancy related at page 7 of the BRITISH MEDICAL JOURNAL for July 4th, 1868 . Mrs. $\mathbf{P}$. continued pretty well up to the end of June 1868, when she complained of frequent sickness, loss of appetite, and great weakness. In the early part of July, she became partially paralysed on the left side, with impaired mental faculties, headache, and increasing exhaustion, followed by the ordinary symptoms of uræmic coma. The urine was loaded with albumen. The extrauterine tumour did not occasion any uneasiness, and had considerably diminished in size, was much harder, of irregular globular conformation, and occupied the right iliac fossa. She died July 16 th. A cadaveric inspection could not be made, in consequence of the insuperable objections of her mother and husband. 